\title{
ANALYSIS OF ECG SIGNALS FOR THE DIAGNOSIS OF PATHOLOGIES IN REAL TIME USING COMPUTATIONAL ALGORITHMS
}

\section{JUAN GRADOS, SANTIAGO RUBIÑOS, RICARDO GUTIERREZ, FREEDY SOTELO, WILVER AUCCAHUASI, ALEX VALDEZ, DENNIS HUAMAN}

Facultad de Ingenieria Electrica y Electronica, Universidad Nacional del Callao, Lima, Perú

\begin{abstract}
This project consists of creating a low-cost ECG device capable of providing a valid self-diagnosis of the heart condition of users who live in remote areas of the city and do not have a specialist who can guide and help them to prevent possible future cardiac diseases, for this it is necessary and essential the database of signals obtained from different types of patients and places of the country which is normalized, filtered with wavelet and sent to the neural network code in Python so that you can learn and have a high degree of certainty in the diagnosis. In addition, all of this is monitored remotely by facilitating the sending of data to a city hospital for verification.
\end{abstract}

KEYWORDS: Self-Diagnosis, Normalization, Filter and Wavelet

Received: Jun 08, 2020; Accepted: Jun 28, 2020; Published: Sep 05, 2020; Paper Id.: IJMPERDJUN20201077

\section{INTRODUCTION}

The study of the following project seeks to deepen the analysis of the electrocardiographic signals using Wavelet Transform which is a digital filter that enables the detection of undesirable signals such as electrical noise and disturbances that may originate due to the movement of the patient, in addition to recognizing patterns of pathology (in the patient to be treated). By analyzing the electrocardiographic signals, it is feasible to diagnose and track the development of the disease and possible symptoms.

Cardiac signal classification systems usually work in conjunction with modules for acquiring and preprocessing the electrical signals of the heart. These modules are required because these systems need the signal obtained to be as clear as possible and free of errors in the acquisition process. The electrical signals of the heart, or the use of an electrocardiogram (ECG), allow us to know the behavior of this organ. These signals indicate a record of all the activity carried out by this muscle and through them it is possible to identify when the heart is working normally or has a fault. [1]

The electrocardiogram (ECG) is a diagnostic tool for extensive abnormalities of the heart. Automatic extraction of ECG characteristics is important to those who measure and record the electrical activity of the heart in exquisite detail. Interpreting these details allows the diagnosis of heart disease.

\section{METHODS \& MATERIALS}

The methods and materials are composed, by the procedures carried out in the development of the investigation, which consists of block diagram, electronic design, the software design and the connection diagram, which are detailed below. 


\section{Heart Signals}

The cardiac signal reflects polarizations and depolarizations. The wave that stands out with the letter P coincides with the depolarization of the atria, and it is smaller than the QRS complex because it is generated by a smaller surface. The wave that stands out with the QRS letters is precisely the demoralization of the ventricles and stands out for being a very high energy pulse (compared to the rest) and very fast, since it must reach the entire ventricular surface at same time (with very little delay) to avoid turbulence in blood flow. Finally, the repolarization of the cells is given by the $\mathrm{T}$ wave, which as seen can be large in amplitude, as the excursion of voltages is great, but is characterized by being a slow wave. [3]

It is possible to obtain the unipolar signals from the bipolar signals according to the following equations.

$\begin{array}{|lll|}\mathrm{DI} & =\mathrm{aVI}-\mathrm{aVR} & \text { (1) } \\ \mathrm{DII} & =\mathrm{aVF}-\mathrm{aVR} & (2) \\ \mathrm{DIII} & =\mathrm{aVF}-\mathrm{aV} 1\end{array}$

Figure 1: Signal Equations.

These leads also analyze the heart in its frontal form. The reading called aVR is normal to the heart and appears negative. The aVL signal is the potential that crosses, where electrical activity travels first to the positive electrode, this means that it moves at the bottom of the ventricle, this causes a biphasic character of the QRS complex. The aVF signal is seen as the electrical activity that travels to the positive electrode, which is why it is a predominant positive trace. [4]

To obtain a unipolar signal, the union of the other two unipolar signals is taken as a reference. Mathematically expressed is:

$\mathrm{aVR}=\mathrm{aVR}$ solo si $\mathrm{aVF}+\mathrm{aVL}=0$
$\mathrm{aVL}=\mathrm{aVL}$ solo si $\mathrm{aVR}+\mathrm{aVF}=0$
$\mathrm{aVF}=\mathrm{aVF}$ solo si $\mathrm{aVR}+\mathrm{aVL}=0$

Figure 2: Signal Equations (Continued).

Obtaining the unipolar leads is one at a time, since the condition for one lead is not the same for the other two. The following equations are obtained from equations (1-3). [5]

$$
\begin{array}{ll}
\mathrm{aVR}=-(\mathrm{DI}+\mathrm{DII}) / 2 & (7) \\
\mathrm{aVF}=(\mathrm{DI}+\mathrm{DII}) / 2 & (8) \\
\mathrm{aVF}=(\mathrm{Di}+\mathrm{DII}) / 2 & (9)
\end{array}
$$

Figure 3: Signal Equations (Continued).

\section{Neural Networks and Computational Algorithms}

Neural networks are being used very frequently in many applications, and medicine is not an exception, therefore its use is based on power in being able to predict certain abnormalities that occur in both signals and images, in the mechanism To predict these anomalies, it is possible to determine the characteristics that will allow determining if the signal is normal or has any pathological change. The success in the use of neural networks in medicine is to be able to determine certain characteristics that allow us to distinguish between a normal signal and a signal with pathology. [6] 
When defining the architecture of a neural network, it is common to group sets of neurons in layers in such a way that all the cells in the same layer behave similarly, that is, they have the same activation functions and connection patterns (generally, neurons are completely interconnected or not connected at all). In this way it is possible to find three types of layers: [7] Input, output and processing layers.

As can be seen, the engineering area has developed and adapted a large number of ECG signal processing and analysis methods, making considerable progress in the early detection and diagnosis of CVD. However, the lack of an adequate understanding of cardiac electrical dynamics makes it difficult to optimize the computational techniques used, resulting in an increase in the number of false positives and therefore a low specificity when issuing a computer-assisted diagnosis. A solution to this type of problem has been the creation of mathematical computational models of cardiac electrical activity that allow the recreation of diverse and complex electrophysiological situations. In this way, sets of ECG signals can be synthesized for training and validation of assisted diagnostic systems. [8]

The Fast Fourier transform is basically defined as a mathematical algorithm, which captures digitized samples in the time domain and in turn calculates their representation in the frequency domain.

Discrete Cosine Transform (DCT). This transform has a good energy compaction property, which produces correlated coefficients, with the difference that the DCT base vectors depend only on the order of the selected transform, and not on the statistical properties of the input data. Its mathematical expression is defined as:

Discrete Wavelet Transform (DWT). Known for the implementation of the signals to detect their noise and possible decompositions of each of the ECG signals, used to design a QRS detector. Its mathematical expression for is defined as. [9]

In practice, when an ECG signal is applied, it presents a lot of noise and interference in its signal, these noises are caused by many factors such as the proper movement of the muscle, by the use of the electrodes and their contact with the skin, noise coming from the electronic components used in the amplification stage, among others, being able to limit these noises are of utmost importance when processing the ECG signal [9]. Traditionally, acquired ECG signals are analyzed in the time domain by expert clinicians. However, pathological conditions may not always be obvious in the original timedomain signal. Therefore, by introducing the analysis of the signal by means of Wavelets, it provides more information on time and frequency, which can overcome this limitation. [10]

The wavelet transform (WT) allows a good representation of the signal both in time and in frequency simultaneously; filters a signal over time using high pass and low pass filters which remove some frequency components from the signal and the process is repeated with the new signals to the desired level. This process is called decomposition.

\section{RESULTS}

At the end of the investigation in the acquisition of the ECG signals and to be able to analyze it through the neural networks, the following conclusions were reached:

The db6 waveform in the use of the ECG signal is present in figure 5, where it shows the different wave forms. 




Figure 4: Wavelet db Waveforms.

Using the LabVIEW interface, we compared the ECG signals, for this the respective analysis was performed where the use of the Butterworth filter in a configuration of order 5 to $60 \mathrm{~Hz}$ was compared with the filtered signal using Wavelets. The signal in Fig. 6 below shows the raw signal from the ECG device.

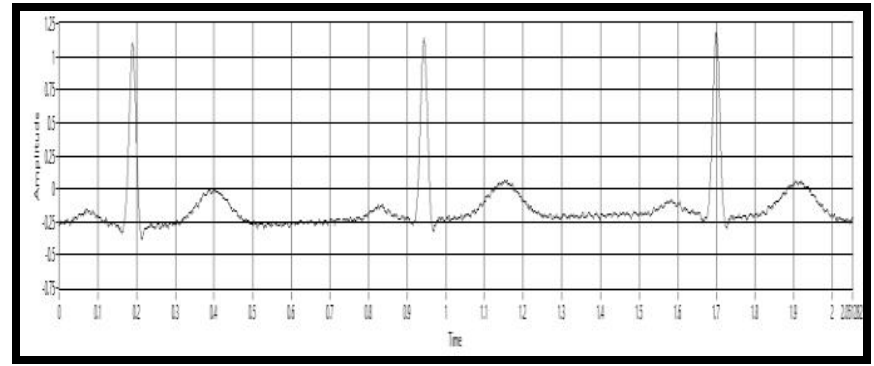

Figure 5: ECG Signal Analyzed from the Device.

It was observed that the direct ECG signal has noise due to the aforementioned interferences.

The filtered signal is shown below using a Butterworth filter of order 5 to $60 \mathrm{~Hz}$, which even filtering the frequency of the alternating network, you can see interference noises in the signal.

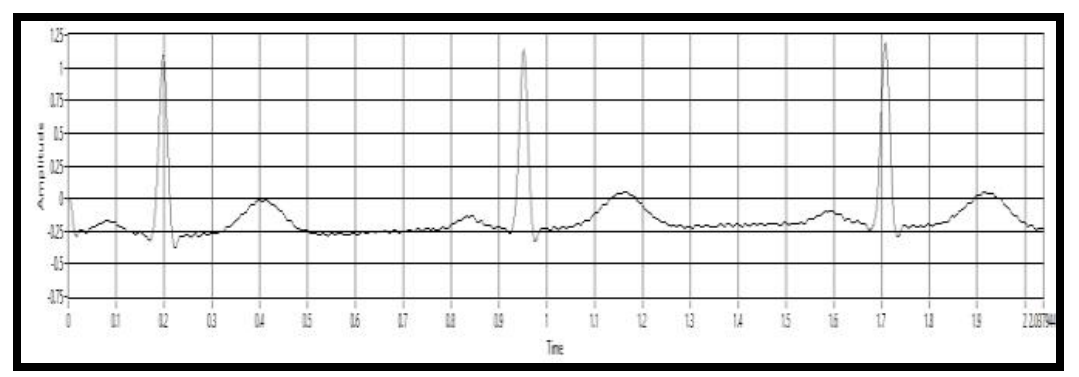

Figure 6: Below Shows the Signal Conditioned by an Order 5 Butterworth Filter.

In the figure 6, the ECG signal passed through a filter design in the Butterworth order 5 configuration, where the cutoff frequency at $60 \mathrm{~Hz}$ was used.

Next, we have the filtered signal using Wavelet with a db6, obtaining a better smoothing and a better view of the characteristics to analyze.

When using the wavelet filter, an enormous improvement is observed with respect to the quality of the signal, as shown in figure 7. 


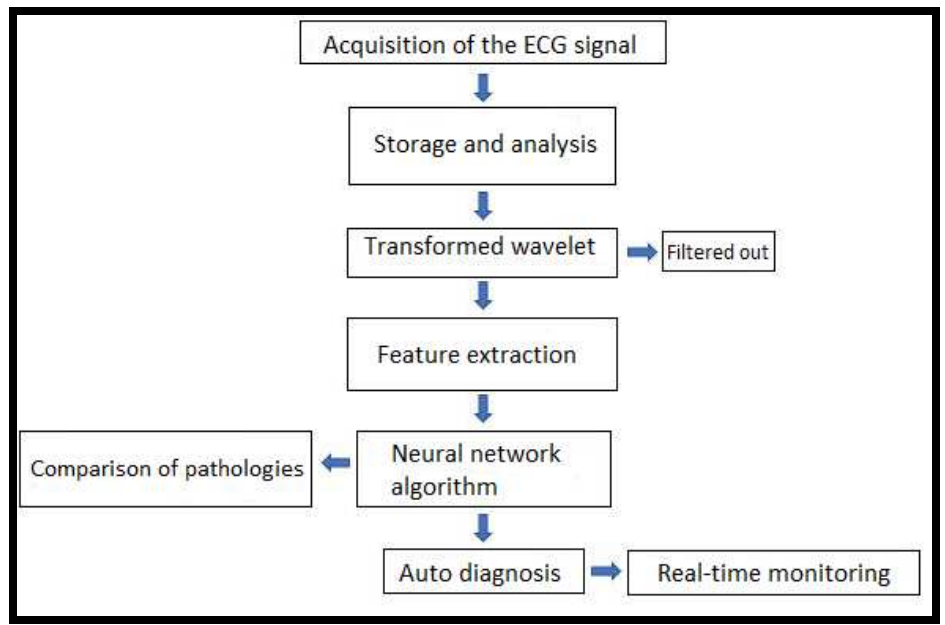

Figure 7: Proposal Block Diagram.

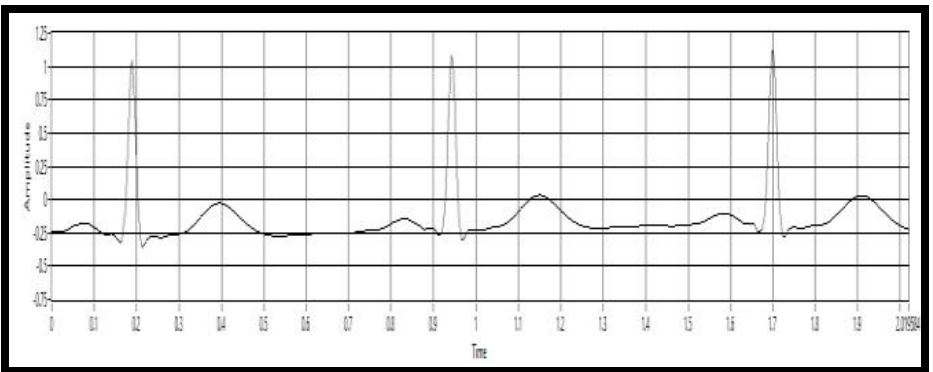

Figure 8: ECG Signal Analyzed by Wavelet Transform.

In the following figure 8 , a flow diagram of the proposal presented is presented graphically.

At the end of the analysis of the signal and having carried out the corresponding filtering processes, the extraction of characteristics was carried out, where the original signal was made and the comparison with the patterns of cardiac pathologies was carried out.

A healthy heart beats 60 to 100 times per minute. Each of these beats constitutes an orderly process of atrial and ventricular contractions and relaxations. [9]

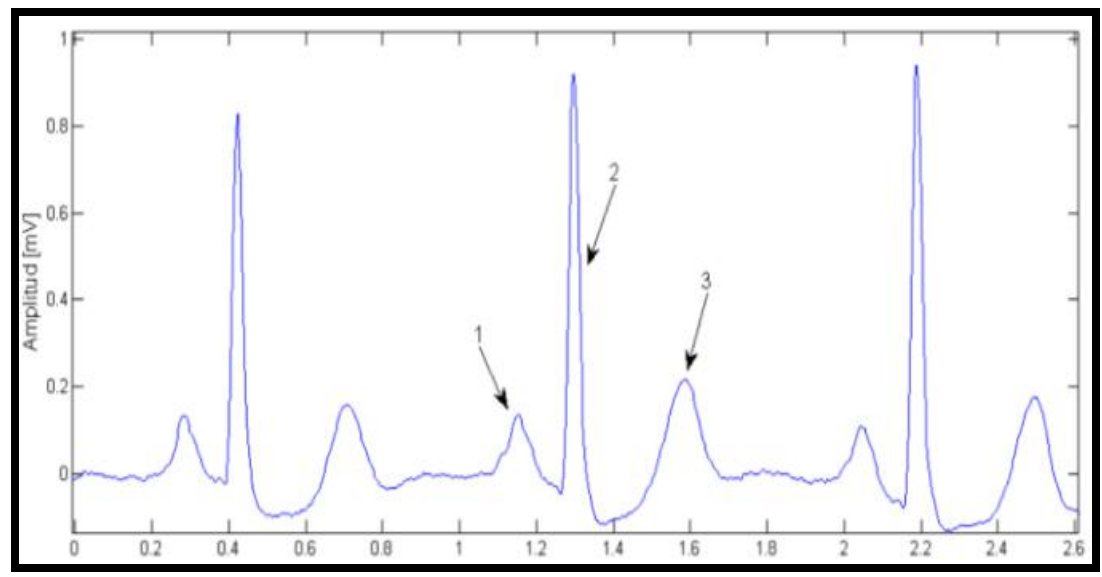

Figure 9: ECG Signal with Normal Sinus Rhythm. 
The database used is from hospitals in Lima and Callao, which allows learning the system, ruling out and selecting the corresponding pathologies for each cardiac signal analyzed.

\section{CONCLUSIONS}

- Electronic devices can be implemented that allow the self-diagnosis of heart disease with little budget.

- The cardiac signals captured by the ECG vary due to its geographical position in Peru, which is influenced by factors such as climate and latitude.

- The signal measurement accuracy index improved by $90 \%$ compared to the analyzed raw signal.

- The degree of approval increased by $80 \%$ in patients from remote locations in Peru.

- The use of Wavelets for signal processing is quite useful and allows improving the quality of the signal.

- Low power consumption of the device, approximately $30 \%$ using LIPO batteries, compared to a switched source for direct power supply from the electrical network.

- The use of db6 of the Wavelet guarantees the correct analysis of the signal with respect to the Butterworth filter used.

- The self-diagnosis that the neural network emits to the device is close to true by $85 \%$.

\section{REFERENCES}

1. Ochoa, A. (2017). Sistema de adquisición y procesamiento de señales electrocardiográficas. Universidad de Colima Coquimatlán, México.

2. Gomez, A. (2014). Análisis de la señal ECG (electrocardiograma) reconociendo las ondas P y T del complejo QRS usando la transformada Wavelet. Madrid, España.

3. Escolá, J. (209). Análisis e implementación de algoritmo de detección de complejos QRS en tiempo real, Universidad Tecnológica Nacional, Buenos Aires, Argentina.

4. J.M. Najeb, Salleh, Sh-Hussain; Yusoff, Khalid; "Two-channel data acquisition unit for heart sound analysis". 1st International Conference on Computers, Communications, \& Signal Processing with Special Track on Biomedical Engineering, 2005 (CCSP 2005). 14-16 Nov. 2005 Page(s):173 - 175.

5. William F. Ganong. “Fisiología Médica”. Editorial El Manual Moderno, S.A. de C.V. 1986.

6. J. Mateo. "Aplicación de redes neuronales artificiales en el procesado versátil de señales electrocardiográficas”. Universidad Politécnica de Valencia, 2012.

7. F. Jeremy. "Caracterización de electrocardiogramas mediante redes neuronales y transformada ondita". Universidad Nacional de Córdoba, Junio del 2014.

8. Liberczuck $S$, Lorena $M, R$. Anderson, Arini. P. Reconocimiento de patrones y modelado en señales de electrocardiograma: detección temprana de squemia e infarto de miocardio.

9. M. Gonzáles. "Análisis de señales electrocardiográficas con isquemia cardiaca usando técnicas de procesamiento digital de señales. Universidad de Manizales. Colombia, 2009. 
10. M. Nageswari, U. Sabura, K, Kumar, S. Maruthi. "Feature extraction of ecg daubechies wavelet and classification based on fuzzy c-means clustering technique.

11. M. Pinzón, R. López. Análisis de señal del impulso cardiaco para el mejoramiento del diagnostico de patologías del corazón. Universidad Tecnológica de Pereira. Colombia, 2011. 
